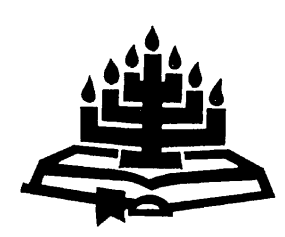

\title{
Is die idee van 'n kerkorde nog kerklik byderwets?
}

\author{
C.J. Smit \\ Skool vir Kerkwetenskappe \\ Potchefstroomkampus \\ Noordwes-Universiteit \\ POTCHEFSTROOM \\ E-pos: neelssmit@lantic.net
}

\section{Abstract \\ Is the idea of a church order still relevant for the modern church?}

The question is whether church order could be of any significance for the church of our time. Should the church order be modernised to fit the church of a new millennium? Is the concept of a church order at all still feasible for the modern church?

Where does the idea of a church order come from? This article shows that the concept of a church order originated from the Scriptures, the Old and the New Testaments. Throughout church history there was always the danger that where the church order became insignificant, the existence of the church itself came under threat.

The real questions are what a church order ought not to be and what it ought to be. This article determined that the church order has no independent authority. The church order should not be rendered as a church law. In fact, the church order should be only the principle-bearing pointer to the Word of God. In itself the church order has no own authority. It is only a servant of the authority of the Word. As such a Scripture-bound church order is indispensable for the existence of the church, also the church of our time. The nature of such a church order is not to create the services of the church, nor the essence of church being, but to ensure the task of the church to proclaim the Word of God and to protect the solemn being of the church in its orderly existence as the people of God in this world. 


\section{Opsomming}

\section{Is die idee van 'n kerkorde nog kerklik byderwets?}

Die vraag is of 'n kerkorde nog enige betekenis vir die kerk van ons tyd kan hê. Behoort die kerkorde gemoderniseer te word om in 'n moderne tyd in te pas? Is die idee van 'n kerkorde nog hoegenaamd haalbaar vir die kerk in ons tyd?

Waar kom die idee van 'n kerkorde vandaan? Hierdie artikel toon aan dat die konsep van 'n kerkorde uit die Skrif kom, uit die Ou- en die Nuwe Testament. Deur die kerkgeskiedenis was daar altyd die gevaar dat waar die kerkorde van minder belang geag is, die kerk se voortbestaan self in gevaar gekom het.

Die regte vraag is wat die kerkorde nie behoort te wees nie en wat dit wel behoort te wees. Hierdie artikel bevind dat die kerkorde geen selfstandige gesag het nie. Die kerkorde moet nie as 'n kerkwet hanteer word nie. Trouens, die kerkorde behoort slegs die rigtingwyser na die Woord van God te wees. In homself het die kerkorde geen gesag nie. Die kerkorde is slegs 'n bedienaar van die gesag van die Woord. As sodanig is 'n Skrifgebonde kerkorde onontbeerlik vir die bestaan van die kerk, ook die kerk van ons tyd. Die aard van sodanige kerkorde is nie om die dienste van die kerk te skep nie, ook nie om die voortbestaan van die kerk daar te stel nie, maar om die kerk se taak om die Woord te verkondig te beveilig én om die wese van die kerk in sy ordelike voortbestaan as die volk van God in hierdie wêreld te beveilig.

\section{Inleidend: vraagstelling}

Is die kerkorde nog in die mode? Is hy nog presenteerbaar en bruikbaar in sy huidige voorkoms? Moet kerke in die gereformeerde tradisie in hierdie tyd van nuwe eise om in 'n veranderende wêreld staande te bly nie maar van die kerkorde afstap en hom onseremonieel en sonder verdriet begrawe nie? Of moet die kerkorde dalk 'n nuwe baadjie aangetrek word, 'n moderne oopnekhemp, en toegerus word met 'n paar modieuse skoene om vaartversnellende tye gepas tegemoet te kan gaan?

Die "ligte aanslag" van die tema en die inleidende vrae moenie misverstaan word nie. Juis deur dié kontrastering wil die relevansie van die vraagstelling beklemtoon word: Watter betekenis het die kerkorde werklik vir die kerk aan die begin van die derde millennium na Christus? Is dit trouens hoegenaamd belangrik om oor die kerkorde te skryf? 
'n Handvol bedenkings in ons tyd kan soos volg verwoord word (vgl. Muller, 2002:36, 37; Smit, 1984a:79):

- Uit die hart van die postmodernisme, waar van 'n "nuwe reformasie" gepraat word, word gevra of die idee van 'n kerkorde werklik toepaslik is. Is 'n kerkorde nie verouderd en belemmerend vir die kerk se vrye ontwikkeling nie, maar tog 'n handige instrument om mense binne die kerk in die Calvyntradisie gevange te hou nie?

- Uit Pentekostalistiese en Charismatiese kringe word gevra of die idee van 'n formele kerkorde werklik houdbaar kan wees. Sou 'n vasgelegde ordereëling die vrye werking van die Gees in die kerk nie afstomp, dit selfs verhinder en die vlam in die kerk doof nie?

- Die drywende Christendom ("church hoppers") wat toeneem, vra nie formeel vrae oor die idee van 'n kerkorde nie, juis omdat 'n kerkorde in dié kring as irrelevant beskou word vir die geloofslewe wat op spirituele spitspunte en geestelike opvlammings speel.

- Skeptiese, maar getroue kerkmense vra soms of die kerkorde nie maar net die hamer is waarmee ordepunte op kerklike vergaderings, ontvanklikheid van stukke, en besluitvorming, in vooraf bepaalde rigtings gemoker word nie?

Voorskrifte, reglemente, kerkordes en selfs geloofsbelydenisse kry ... 'n ondergeskikte funksie. Nooit meer kan hierdie historiese dokumente die essensie van iets bepaal nie, wel 'n woordeskat gee waarteen ons die huidige gang van ontwikkeling kan spieël (Muller, 2002:36).

\section{Kort historiese oorsig - en verdere vrae}

Dit mag oorskat klink, maar die idee van 'n kerkorde is so oud soos die Nuwe-Testamentiese kerk self. Selfs in die Ou Testament was daar al sprake van "formele kerkordening".

In die Ou-Testamentiese tye was die regeringsvorm 'n teokrasie (Godsregering). Kerk en staat was 'n eenheid wat in dieselfde regeringstelsel georden is. Die Mosaïese wette het in oud-Israel tegelykertyd gedien vir sowel die ordening van die godsdienslewe ( $q a \bar{a} h \bar{l}$ l as kerk) as vir dié van die staatsbestel (vgl. Koehler-Baumgartner, 1958:829). Vanaf pinkster het daar 'n skeiding tussen kerk en staat gekom. Die kerk (ekklésia) het oor die grense van alle volke begin uitbrei, nie meer net binne die grense van die een Ou-Testamentiese godsvolk met sy teokratiese regeringsvorm nie (vgl. 
Ridderbos, 1971:365-368), en moes daarom 'n eiesoortige, ordelike lewenswyse onder die bestel van heidense owerheidstelsels verkry. Die eie bestaan en regering van die kerk as 'n unieke, eiesoortige liggaam in die wêreld moes van die begin af as 'n nuwe lewensorde binne die raamwerk van die Skrif gereël word (Smit, 1984a:83 e.v.).

Merkwaardig genoeg vind ' $n$ mens dus alreeds vanaf die vervalling van die teokrasie die idee van 'n kerkorde waarvolgens Christus se regering oor sy kerk gehandhaaf kon word. Daar is teoloë wat die eerste kerkordes al in die Nuwe Testament wil aantoon, byvoorbeeld in 1 Korintiërs 5-14 en 1 Timoteus 2-3:13 (Smit, 1984a:88).

Nietemin, die Didaché is 'n kerkorde waarvan ons weet, wat as een van die heel oudste kerklike dokumente uit die tyd van die apostels kom, en wat moontlik voor sommige Nuwe-Testamentiese geskrifte in die tweede helfte van die eerste eeu ontstaan het; die Didaskalia of Ordeninge van die Apostels het in die derde eeu in Sirië ontstaan; die Traditio Apostolica of Apostoliké Paradosis van Hippolytos het in die begin van die derde eeu ontstaan; en die Diataghai, of Constitutiones Apostolorum het in die tweede helfte van die vierde eeu ontstaan (Smit, 1984a:88 e.v.).

In die Roomse tradisie is bepalings vir die kerkregering, wat vanaf die vierde eeu in die pouslike stelsel - weliswaar nie ondergeskik aan die Skrif nie, maar as gelyke naas die Skrif - ontwikkel het, sedert 1140 n.C. in die Corpus Iuris Canonici saamgevat. Hierdie dokument, ook bekend as die Decretum Gratiani en uitgegee onder die titel, Concordia Discordantium Canonum, het uit 'n versameling kodekse, kerkwette en canones bestaan. In 1918 is die Corpus luris Canonici georden en gesistematiseer onder die nuwe titel, Codex Iuris Canonici. Laasgenoemde is op sy beurt in 1983 weer hersien en verfyn. Hiertoe het die huidige pous, Benedictus VI, as Joseph Ratzinger, 'n beduidende bydrae gemaak (Smit, 1985:18).

Verskeie kerkordes het in die reformatoriese tradisie vanaf die vroeë sestiende eeu as korreksie op die Roomse kerkregeringstelsel verskyn, waarvan die kroonjuweel die Dordtse Kerkorde is. Hierdie kerkorde is die resultaat van 'n lang en intensiewe ontwikkelingslyn, waartydens die Skrifbeginsels vir kerkregering op 'n merkwaardige wyse aan die hand van prinsipiële vraagstukke sowel as praktiese kwessies uitgekristaliseer het. Calvyn se beskouing oor kerkregering het 'n grondliggende invloed op die vorming van die Dordtse Kerkorde gehad. Sy Ordonnances Ecclésiastiques wat hy in 1541 in Genéve geïmplementeer het, die Londense Kerkorde van 1554 wat deur a'Lasco en Micron opgestel is, die Discipline Ecclésiastique 
wat in 1559 deur 72 Franse gemeentes opgestel is en die Waalse Kerkorde wat tydens verskeie sinodes vanaf 1563 tot 1566 opgestel is, was die historiese voorspel tot die konsepkerkorde wat op die Konvent van Wezel in 1568 opgestel is. Vanaf Wezel loop die ontwikkelingslyn van die kerkorde via die sinodes van Emden (1571), Dordrecht (1574), Dordrecht (1578), Middelburg (1581) en 's Gravenhage (1586) tot Dordrecht (1618-1619) waartydens die Dordtse Kerkorde sy uiteindelike beslag gekry het. Hierdie kerkorde word steeds, in aangepaste vorm vanweë kultuur- en tydsomstandighede, deur verskeie gereformeerde kerke in die wêreld gebruik (Smit, 1984a:116).

Vanaf die Reformasie het kerkgemeenskappe in die gereformeerde tradisie die kerkorde deurentyd as noodsaaklik vir die goeie orde in die kerk geag (Calvyn, 1956:IV.I.5; IV.VIII.1; IV.X.1.27.32; Bouwman, 1970:65-74, 327; Jansen, 1923:2; Monsma, 1967:19, 20; Hovius, 1962:37; Nauta, 1971:7-9, 14; Plomp, 1967:18; Barth, 1958: 680, 681; Wehrhahn, 1956:65, 66; Van der Linde, 1983:7, 8; Coertzen, 1991:175 e.v.). Hovius (1962:37) stel die noodsaaklikheid van die kerkorde so sterk dat dit geheel en al die wese van die kerk raak: "Waar eenmaal het ecclesiologisch docetisme geleid heeft tot minachting van de kerkorde, bedreigt ontbinding het kerklijk leven!"

Tog was daar in die gereformeerde tradisie van tyd tot tyd vrae gestel oor die wenslikheid, die funksie en die plek van 'n kerkorde (vgl. Van den Berg, 1969:11, 13, 51, 56, 68, 69; Brouwer, 1937:7-9, 90). Die argument teen die noodsaaklikheid en selfs die wenslikheid van 'n kerkorde word verteenwoordig in die beskouing dat 'n kerkorde 'n bundel kerklike insettinge is waardeur die kerk as 't ware "ingekerker" word en as sodanig ook 'n historiese ergernis is waaraan hoegenaamd geen waarde toegeken behoort te word nie (Van den Berg, 1969:56).

In die besonder het die Gereformeerde Kerke in Suid-Afrika hulle onderskei in die onderhouding van die Gereformeerde Kerkorde. Maar hou al dié kerke hulle nog konsekwent aan bepalings van die kerkorde - byvoorbeeld oor sinodebesluite waaroor die Gereformeerde Kerkorde bepaal: "Wat op 'n kerklike vergadering met meerderheid van stemme besluit is, moet as vas en bindend beskou word, tensy dit bewys word dat dit in stryd is met Gods Woord of die artikels van die Kerkorde." (KO, 1980, art. 31.)? Vanaf die Gereformeerde Kerke se sinode in 2003 het bepaalde kerke in dié kerkverband ernstige besware teen sinodebesluite geopper. Sommige van hierdie kerke het in die openbaar verklaar dat hulle hul nie deur dié besluite gebonde ag nie - ondanks die bepaling van 
artikel 31 van die Gereformeerde Kerkorde en sonder dat die betrokke besluite in meerdere vergaderings as strydig "met Gods Woord of die artikels van die Kerkorde" bewys is (vgl. Du Plooy, 2005:18-20).

Die vraag oor die kerkorde loop wyer. In 'n postmoderne tyd waarin die gesag van instellings al hoe meer bevraagteken word, gaan dit vir al hoe meer lidmate uiteindelik oor die vraag na die "gesag" van die kerkorde en die reg van die kerk om hedendaagse gelowiges aan 'n historiese kerklike dokument te onderwerp (vgl. Vorster, 1999:107, 111; Smit \& Vorster, 2000:519).

Om 'n antwoord op genoemde vrae te kry, word in hierdie artikel éérs vasgestel wat 'n kerkorde veral nie behoort te wees nie en daarna wat 'n kerkorde wel behoort te wees.

\section{Wat 'n kerkorde nie behoort te wees nie}

'n Kerkorde behoort nie 'n kerklike wet naas die Heilige Skrif te wees, wat sy gesag aan homself ontleen nie. 'n Kerkorde dwing ook nie, soos 'n staatswet, nakoming deur strafmaatreëls af nie. Eweneens behoort 'n kerkorde ook nie 'n stel reëls en reglemente van kerklike vergaderings te wees wat bloot van regsadministratiewe of kontraktuele belang vir die kerk is nie (Smit, 1985:371 e.v.).

Die toepassing van 'n kerkorde behoort nie 'n rigiede afdwinging van die reg te wees wat deur 'n "owerheid" bepaal word nie, maar 'n ordereëling waardeur die beginsels van die kerkregering wat in die Skrif gegee is, sistematies weergegee word. ' $n$ Oortreding van 'n kerkordereëling behoort dus nie 'n oortreding vanweë die kerkorde self te wees nie, maar wél 'n oortreding in soverre dit teen 'n Skrifbepaling ingaan (Smit, 1985:374 e.v.)

Wat hier gestel is, kom daarop neer dat 'n kerkorde nie 'n juridiese instrument is wat ter wille van sy eie gesag afgedwing moet word nie. Trouens, ' $n$ kerkorde is volkome van die Skrif afhanklik. Die aard van 'n kerkorde bepaal sy andersheid ten opsigte van 'n "kerkwet". 'n Kerkorde behoort die Skrif in die kerklike organisasie aan die woord te stel. Op so 'n wyse word Christus in elke aspek van die kerkregering herkenbaar. In werklikheid behoort 'n kerkorde vir die doel van die kerkorganisasie en die kerkregering niks anders te wees nie as die kerklike weg na die Skrif, waarin Christus die beginsels vir die ordening van sy kerk op aarde gee (Smit, 1985:376 e.v.). 
Wat 'n kerkorde nie behoort te wees nie, kan soos volg saamgevat word (Smit, 1987:24):

- 'n Kerkorde skep nie die kerklike dienste ("ampte") nie, maar gee dit weer.

- 'n Kerkorde konstitueer nie die kerklike vergaderings nie, maar gee ordelike beslag daaraan.

- 'n Kerkorde stel nie die Woordverkondiging en die sakramentsbediening daar nie, maar beveilig en handhaaf dit.

- 'n Kerkorde beveel nie die kerklike tug nie, maar reël hierdie Skrifopdrag ordelik tot kerklike prosedure.

- 'n Kerkorde skep nie die kerkinstituut nie, maar handhaaf die Skrifbeginsels daarvoor en gee dit weer (waaronder die reëlings vir die roeping en bevestiging van die onderskeie dienaars, vir die kerklike vergaderings, die leer, sakramente en ander seremonies asook die kerklike tug).

- 'n Kerkorde is veral van belang vir die beveiliging van die kerkverband waarin die eenheid van die kerk van Christus sigbaar word, en derhalwe 'n beskerming teen individualisering van kerke in 'n independentistiese kaleidoskoop van kerke.

\section{Wat 'n kerkorde behoort te wees}

Hierbo is bevind dat 'n kerkorde, teenoor die Roomse beskouing, geen "kanonieke reg" benewens die Skrif bied nie, maar dat 'n kerkorde die hulpmiddel behoort te wees waarin die wyse saamgevat en gesistematiseer is waarop Christus, as die organiese Hoof en enigste Regeerder van sy kerk, die kerk volgens sy Woord wil regeer (vgl. Coertzen, 1991:176 e.v.).

In 'n kerkorde gaan dit dus hoofsaaklik om die Skrifbepalings vir die daarstelling en onderhouding van die dienste, die kerklike vergaderings (dus in kerkverband), die leer, sakramente en ander seremonies en die handhawing van die kerklike tug. Praktiese reëlings en prosedurebepalings behoort so min moontlik in 'n kerkorde opgeneem te word en slegs waar dit noodsaaklik en nie strydig met die Skrif is nie. Op hierdie wyse moet ' $n$ kerkorde as 'n instrument dien waardeur Christus die kerk self deur sy Woord en Gees regeer (vgl. Calvyn, 1956:IV.X.30; Bouwman, 1970:327; Jansen, 1923:2; Monsma, 1967:19, 20; Van der Linde, 1981:183). 
In werklikheid behoort 'n kerkorde die Skriftuurlike modus quo vir die kerkregering te wees. Die Skrifbeginsels wat deur 'n kerkorde weergegee word, vorm die konstitutiewe element van die kerkorde. Die praktiese ordereëlings, prosedures, ensovoorts, val onder die aspek van die betreklikheid en vorm die institutiewe deel van 'n kerkorde. Laasgenoemde aspek van 'n kerkorde mag en móét verander word as die uiterlike omstandighede ter wille van die opbou van die kerk dit vereis: aedificatio ecclesiae suprema lex - "die opbou van die kerk is die hoogste wet" (vgl. Rutgers, 1890:39, 40; Van der Walt, 1976:161; De Jong, 1967:18).

'n Kerkorde behoort 'n rigtingpyler te wees na die Skrif, waardeur verhinder kan word dat die kerk in 'n "eie wetlikheid" verval waar die hoogste gesag in die praktyk naderhand die meerderheidstem van menslike beoordeling is (vgl. Jonker, 1965:11-14; Van der Walt, 1976:6; Sadler, 1979:564 e.v.).

Omdat 'n kerkorde nie 'n wet is nie, eis die kerkorde uit die Skrifbeginsel van liefde vrye gehoorsaamheid - nie gehoorsaamheid aan 'n menslike gesagsinstansie of aan die mediaan (deursnee gelowige) se opvatting oor hoe kerklike aangeleenthede ingerig en gehanteer moet word nie, maar gehoorsaamheid aan die Skrif. Tegelyk moet die kerklike belydenis as die norm van die kerkorde terdeë in ag geneem word, sowel met die samestelling as die toepassing van die kerkorde. Die kerkregtelike beginsels waardeur die kerkorde bepaal word, moet ook in elke gegewe situasie nagevors word ter wille van die opbou van die kerk. Hierby moet die geskiedenis van die kerkorde oor die algemeen en dié van die ter saaklike artikel in die besonder behoorlik in ag geneem word met die toepassing daarvan.

Wat 'n kerkorde behoort te wees, kan soos volg saamgevat word (Smit, 1984b:44):

Die kerkorde is in die Heilige Skrif gefundeer en daardeur vanweë die belydenis genormeer; die kerkorde word deur die kerkreg geformeer en geprogrammeer en deur sy geskiedenis gesitueer.

\section{Die gesag van 'n kerkorde?}

Die vraag na die gesag van die kerkorde is tegelyk ' $n$ vraag na die gesag van die kerk. Wanneer vanuit die mens as vertrekpunt oor die kerk nagedink word, en nie vanuit die Skrif as die openbaring van God nie, is die kerk niks meer nie as 'n instituut, 'n natuurlike 
gemeenskap wat volgens die wetmatighede en reëls van enige ander menslike vereniging bestaan (Brunner, 1939:194, 318). Die kerk sou dan, soos enige ander gesagstruktuur, vir homself die gesag kon toeëien wat enige ander samelewingsverband kragtens die natuurlike reëls van gesagsvorming toekom.

Indien die kerk egter as 'n produk van die herskepping in en deur Jesus Christus gesien word (vgl. Kuyper, 1909:227), moet die kerk vanuit "de orde en de gestalte der regeringsinrichting, die Hij zelf heeft voorgeschreven" verstaan word (Calvyn, 1956:IV; VI.9). Die gesag van die kerk moet dan nie in homself gesoek word nie, maar in sy Regeerder, kragtens wie se opdrag en grasie die kerk bestaan.

Uitgaande van die Skrifgronde vir die bestaan van die kerk, moet opgemerk word dat die kerk 'n unieke, eiesoortige liggaam is. Die kerk is die liggaam van Christus op aarde - eintlik 'n vreemde orgaan in die wêreld wat gedurig aan verwerping blootgestel is. As liggaam van Christus is die kerk die beliggaming en draer van God se nuwe orde in die ou en verloregaande wêreld (Milner, 1970:4 e.v.).

So gesien, is die orde waarvolgens die kerk leef en uitgebou word wesenlik anders as die orde van enige ander samelewingsverband, instituut, of struktuur. Dit beteken dat die beginsels van die regering van hierdie unieke gemeenskap, waardeur God se nuwe orde in die wêreld vergestalt word, deur Homself in sy Woord verorden word. Derhalwe setel die gesag van hierdie gemeenskap, die kerk, primêr in die Woord van God. Hyself is die Gesagvoerder en sy gesag het Hy aan niemand oorgedra nie (Smit, 1985:349-352).

'n Kerkorde, as die formulering van die modus quo van die organisasie en regering van hierdie nuwe orde in sy institusionele verskyning, het dus nie naas die Woord van God gesag in homself nie. Die gesag van die Woord word nooit die gesag van die kerkorde nie. Hier vind geen gesagsoordrag plaas nie. In die Woord spreek God by monde van gelowiges wat Hy eenmalig in besondere omstandighede deur sy Gees daarvoor geroep het. In 'n kerkorde praat gelowiges die Woord ten opsigte van die kerkregering gehoorsaam na.

Insgelyks beteken dit ook dat dié wat deur Christus as dienaars in sy kerk geroep is, en wat die opdrag tot kerkregering (derhalwe ook die toepassing van die kerkorde) kragtens hulle roeping ontvang het, nie 'n eie gesag vir dié taak ontvang het nie. Christus dra eweneens nie sy gesag aan sy dienaars oor nie, maar Hy oefen sy gesag deur sy 
dienaars uit: "Wat Christus beveelt, heeft absoluut gezag, maar de opzieners der gemeente hebben uit zichzelven niets te zeggen, maar alleen als bedienaars des Woords" (Bouwman, 1970:2). Die klem val nie op die bedienaars as "ampsdraers" nie - die gesag setel nie in die "amp" nie. Die klem val op "bedienaars des Woords" - die gesag setel in die Woord. So word die korrekte toepassing van die kerkorde die bediening van die gesag van God uit sy Woord onder leiding van sy Gees.

Ook vir die Reformatore was die vraag na kerkordelike gesag 'n vraag na die gesag van die kerk. Vir Bucer het dit beteken dat kerkordelike gesag, en derhalwe kerklike gesag, slegs 'n bediening van die gesag van die Skrif moet wees. Sonder 'n duidelike verwysing na Skrifbeginsels hou die kerkorde vir hom geen gesag in nie. Die regering van die kerk kom dus vir hom suiwer neer op Christusregering - deur die opdragte en bepalings wat Christus vir sy kerk in die Skrif gegee het (Van't Spijker, 1972:27, 28).

Vir Calvyn (1956:IV.II.4; IV.III.1.2.7.8.14; IV.VII.23; IV.VIII.1-4.7.8) gaan dit in die kerkregering eweneens geheel en al om Christus wat deur sy Woord en Gees regeer. Daarvoor gebruik Hy die herders en opsieners, of ouderlinge. Die kerk is daar waar die orde van Woordbediening, sakramentsbediening en die toepassing van die kerklike tug gehandhaaf word. Die drie vorms van kerklike gesag wat Calvyn handhaaf, naamlik potestas regiminis (reëlende gesag), potestas docenda (lerende gesag) en potestas gubernatio (regerende gesag) fundeer hy konsekwent op die Skrif. As sodanig is "kerklike gesag" vir Calvyn nie 'n selfstandige gesag wat in die kerk setel nie, maar 'n gesag wat volkome aan die Skrif onderworpe is en daardeur begrens word. Die kerk se bevoegdheid om ook praktiese, organisatoriese kerkordelike reëlings daar te stel, rus eweneens op Skrifgesag (1 Kor. 14:40; vgl NGB, 1976: art. 32). Nogtans moet hierdie regulatiewe kerkordelike bepalings, volgens Calvyn (1956: IV.X.30), tot die allernoodsaaklike beperk word en dit mag nie in die geringste mate met die strekking en gees van die Skrif bots nie.

\section{Die noodsaaklikheid van 'n Skriftuurlike kerkorde: 'n gevolgtrekking}

Die noodsaaklikheid van 'n Skriftuurlike kerkorde lê in die aard van die kerk. Die kerk is by uitstek Christus se regeringsdomein en 'n Skrifgetroue kerkorde is niks anders nie as 'n sistematiese samevatting van Christus se bepalings vir die kerkregering. As sodanig is die kerkorde 'n geestelike instrument waardeur Christus se regering 
oor sy kerk sigbaar kan word. Op hierdie wyse kan die kerkregering eintlik 'n Woordregering wees. Sodoende kan wanorde en vervalsing uit die kerk geweer word, die dienaars kan op 'n skriftuurlike wyse beroep en bevestig word, die toesig oor die Woordbediening en die bediening van die sakramente kan in waarheid uitgeoefen word, en die lidmate kan op 'n ordelike weg gelei word om die Here in gehoorsaamheid te dien.

As antwoord op die aanvangsvrae uit 'n skeptieswordende, postmoderne geloofsgemeenskap kan die noodsaaklikheid van 'n Skrifgefundeerde kerkorde saamgevat word in drie B's: Bewaring, Beskerming en Beveiliging.

- Bewaring teen 'n eie manier van kerkregering, 'n eie manier van kerkwees waarin die heerskappy van die Woord nie meer geld nie. Dit kan nie anders as om uit te loop op die ontbinding van die kerkverband nie - en selfs ook van die kerk as sodanig.

- Beskerming daarteen dat die volk van die Here nie meer die stem van die Goeie Herder sal herken nie en in 'n eie wetlikheid sal versink, asof ons bepalings sy bepalings en ons regering sy regering is - kortweg, dat sy kerk nie ons kerk sal word nie.

- Beveiliging van die Woordbediening, sodat die kinders die Vader se stem mag hoor en nie van Hom vervreemd sal raak in 'n gefabriseerde kerk wat eintlik 'n menslike konstruksie is nie.

Die noodsaaklikheid van die kerkorde lê nie daarin dat dit die voorwaarde vir die saligheid is nie, maar wel daarin dat dit die weg van die saligheid beveilig; dat dit die "senuwees" van die kerk bevat wat die kerk van misvorming en verstrooiing bewaar; daarin dat dit die heerskappy van Christus in sy kerk bedien en as sodanig die grondslag van die ordelike voortbestaan van die kerk vorm; en daarin dat die ontkenning van die waarheid wat deur die kerkorde bedien word, na die verwatering van die kerk sal lei, sodat die kerk uiteindelik 'n bloot menslike organisasie met selfgemaakte wette verteken sal word.

Die argumente dat die idee van 'n kerkorde ontoepaslik en verouderd en belemmerend vir die kerke se geestelike ontwikkeling sou wees en dat dit bloot as 'n handige manipuleringsinstrument op kerklike vergaderings gebruik sou word, word in hierdie artikel afgewys - op voorwaarde dat dit om 'n Skriftuurlike kerkorde gaan. Teenoor hierdie argumente word gestel dat 'n Skrifgefundeerde kerkorde wat reg toegepas word, kerkverwatering en selfs kerkontbinding sal teëwerk en juis as 'n onmisbare instrument vir 
kerkbou gegee is. Die idee van 'n Skrifgefundeerde kerkorde is vandag nog net so byderwets as wat dit vir die bloedjong kerk in Paulus se tyd was!

\section{Slot}

Die kerkorde stel die kerk voor sy historiese afgrensing van die wêreld, maar dit stel die kerk óók voor sy eskatologiese oorwinning oor die wêreld. Dit lei tot die insig dat deur die toepassing van 'n Skriftuurlike kerkorde die kerk herinner behoort te word aan 'n Vaderhand wat op die kerk gelê is, 'n hand wat vas en veilig lei, sodat 'n mens mag weet hoe om jou in die huis van God te gedra.

\section{Geraadpleegde bronne}

BARTH, K. 1958. Church dogmatics. Vol. 4, part 2. Translated by G.W. Bromiley. Edinburgh: Clark.

BOUWMAN, H. 1970. Gereformeerde kerkrecht. Deel 1. Kampen: Kok.

BROUWER, A.M. 1937. De kerkorganisatie der eerste eeuw en wij. Baarn: Bosch \& Keuning.

BRUNNER, E. 1939. Das Gebot und die Ordnungen: Entwurf einer protestantisch-theologischen Ethik. Zürich: Zwingli.

CALVYN, J. 1956. Institutie of onderwijzing in de Christelijke godsdienst. Uit Latyn vertaal deur A. Sizoo. Delft: Meinema.

COERTZEN, P. 1991. Gepas en ordelik - 'n teologiese verantwoording van die orde vir en in die kerk. Pretoria: RGN-Uitgewers.

DE JONG, P.Y. 1967. The genius of reformed church polity. Glenside: Reformed Ecumenical Synod.

DU PLOOY, A. le R. 2005. Kerkeenheid, kerkverband en kerkskeuring. Die Kerkblad: 18-20, Maart.

GEREFORMEERDE KERKE IN SUID-AFRIKA. 1980. Kerkorde van die Gereformeerde Kerke in Suid-Afrika, soos gewysig deur verskillende sinodes. Potchefstroom: Calvijn Jubileumboekefonds.

HOVIUS, J. 1962. Het verband tussen onze belijdenis en onze kerkorde. Sneek: Weissenbach.

JANSEN, J. 1923. Korte verklaring van de kerkenordening. Kampen: Kok.

JONKER, W.D. 1965. Om die regering van Christus in sy kerk. Pretoria: Unisa.

$\mathrm{KO}$

kyk GEREFORMEERDE KERKE IN SUID-AFRIKA.

KOEHLER, L. \& BAUMGARTNER, W. 1958. Lexicon in Veteris Testamenti Libros. Leiden: Brill.

KUYPER, A. 1909. Encyclopaedie der heilige Godgeleerdheid. Deel 3. 2e dr. Kampen: Kok.

MILNER, B.C. 1970. Calvin's doctrine of the church. Leiden: Brill.

MONSMA, M. 1967. The new revised church order commentary: a brief explanation of the church order of the Christian Reformed Church. Grand Rapids: Zondervan.

MULLER, P. 2002. Die postmoderne gelowige. (In Muller, P., red. Die Nuwe Hervorming. Pretoria: Protea Boekhuis. p. 19-37.) 
NAUTA, D. 1971. Verklaring van de kerkorde van de Gereformeerde Kerken in Nederland. Kampen: Kok.

NEDERLANDSE GELOOFSBELYDENIS. 1976. (In Die Psalmboek. Wellington: NGB NG Kerk-Uitgewers.)

\section{Kyk NEDERLANDSE GELOOFSBELYDENIS}

PLOMP, J. 1967. Beginselen van reformatorish kerkrecht. Kampen: Kok. (Kamper Cahiers, nr. 4.)

RIDDERBOS, H. 1971. Paulus: ontwerp van zijn theologie. 2e dr. Kampen: Kok.

RUTGERS, F.L. 1890. De geldigheid van de oude kerkordening der Nederlandsche Gereformeerde Kerken. Amsterdam: Wormser.

SADLER, T.H.N. 1979. 'n Pleit teen reglementering van die kerkreg. Die Kerkbode, 131(18):564-565.

SMIT, C.J. 1984a. God se orde vir sy kerk - 'n beskouing oor kerkorde. Pretoria: NG-Kerkboekhandel.

SMIT, C.J. 1984b. Tot lof van die kerkorde ... in sy dienskneggewaad (1). In die Skriflig, 18(71):37-44.

SMIT, C.J. 1985. Kerkreg en kerkorde in die lig van God se orde vir sy kerk. Potchefstroom. PU vir CHO. (Th.D.-proefskrif.)

SMIT, C. J. 1987. Kerkreg en kerkorde in diens van kerkregering: oorsig oor 'n beskouing. In die Skriflig, 21(82):17-27.

SMIT, C.J. \& VORSTER, J.M. 2000. Die GKSA en sy Gereformeerde identiteit kan dit behou word in 'n postmoderne gemeenskap? In die Skriflig, 34(4):515-533.

VAN DEN BERG, M.R. 1969. De gekerkerde kerk. Amsterdam: Buijten \& Schipperheijn.

VAN DER LINDE, G.P.L. 1981. Kerkreg. Deel 1. Klasdiktaat van die Teologiese Skool, Potchefstroom, PU vir CHO. (Ongepubliseer.)

VAN DER LINDE, G.P.L. 1983. Die kerkorde: 'n verklaring van die Gereformeerde kerkorde. Pretoria: T.G. van Wyk.

VAN DER WALT, J.J. 1976. Christus as Hoof van die kerk en die presbiteriale kerkregering. Potchefstroom: Pro Rege.

VAN'T SPIJKER, W. 1972. Goddelijk recht en kerkelijke orde bij Martin Bucer. Kampen: Kok. (Apeldoornse Studies, nr. 3.)

VORSTER, J.M. 1999. 'n Waarskynlike bedieningsmilieu vir die GKSA in die dekades na 2000. In die Skriflig, 33(1):99-119.

WEHRHAHN, H. 1956. Kirchenrecht und Kirchengewalt: Studien zur Theorie des Kirchenrechts der Protestanten auf lutherischer Lehrgrundlage. Tübingen: Mohr.

\section{Kernbegrippe:}

kerk

kerkorde

kerkregering

kerkverband 


\section{Key concepts:}

church

church community church government church order 